

\title{
Napoleão como Filoctetes
}

\section{Apropriação de um mito grego em uma caricatura antinapoleônica Mateus Dagios ${ }^{1}$}

Resumo: O objetivo do artigo é apresentar um caso de reapropriação do mito de Filoctetes na caricatura antinapoleônica, Nicolas Philoctète dans l'Îsle d'Elbe (1814-1815), em que Napoleão em Elba é pejorativamente associado a Filoctetes em Lemnos. Antiguidade, discurso nacional e caricatura misturam-se para compor um Napoleão ferido e abandonado, um caso em que as virtudes guerreiras se transformam em chacota na pena de um artista desconhecido, que recria o quadro do pintor neoclássico francês Guillaume Guillon Lethière, Philoctète dans l'île déserte de Lemnos (1798), para uma releitura pejorativa do mito do arqueiro na figura de Napoleão.

Palavras-chave: Filoctetes, Napoleão, caricatura

\section{Napoleon as Philoctetes}

\section{Appropriation of a Greek myth in anti-Napoleonic caricature}

\begin{abstract}
This paper aims to present an instance of reappropriation of the myth of Philoctetes in an anti-Napoleonic caricature, Nicolas Philoctète dans l'Îsle d'Elbe (1814-1815), in which Napoleon on Elba is associated in a derogatory manner to Philoctetes on Lemnos. Antiquity, national discourse and caricature combine to compose a wounded, abandoned Napoleon, and the warrior virtues are ridiculed by an unknown artist who recreates a painting by the neoclassical French painter Guillaume Guillon Lethière, Philoctète dans l'île déserte de Lemnos (1798), in order to reinterpret the myth in a disparaging, anti-Napoleonic way.
\end{abstract}

Keywords: Philoctetes, Napoleon, caricature

\footnotetext{
${ }^{1}$ Doutor em História - Universidade Federal do Rio Grande do Sul (UFRGS).

E-mail: mateusdagios@yahoo.com.br
} 


\section{Introdução}

Norwood Young, historiador inglês (1860-1943) que se dedicou a compilar e estudar fontes sobre os dois exílios de Napoleão, principia seu Napoleon in Exile com a seguinte observação: "O episódio de Elba da carreira de Napoleão não recebeu a atenção que merece. Ele revela para nós o homem livre do fardo do Império e que ainda não havia dado lugar à pose para a posteridade" ${ }^{2}$. Como todo historiador, Norwood faz a prosaica reclamação que reivindica mais estudos para seu objeto, mas o que nos interessa em sua frase é como ele desenha um Napoleão altivo, ainda consciente que executaria um último ato. Esse traço só pode ser desenhado por quem já conhece os próximos movimentos do Imperador: fuga, Governo dos 100 dias, Waterloo e Santa Helena. Contudo, sem esse olhar retrospectivo, mas tomando em consideração a situação que o exilou em Elba, os relatos que cercam sua situação na ilha e a caricatura napoleônica produzida no período, Napoleão passaria para a posteridade como um tirano isolado ou um imperador fracassado.

Antes de atentar para as representações do período que as caricaturas nos possibilitam entender, é importante ressaltar os limites e alcances da caricatura para o historiador. No jogo das representações políticas, a caricatura coloca em cena um tipo peculiar de expressão, uma linguagem que pela sátira recontextualiza os atores políticos e coloca o cenário social em outra dimensão de observação. Nas possibilidades de representação, ela reconstrói os corpos, animaliza-os, deforma as proporções, reconstruindo-os de maneira que sejam identificados por suas fraquezas e potências.

O exercício de pesquisa proposto parte desse jogo de representações e configurações possíveis nas regras da caricatura para desenvolver uma análise da figura satírica Nicolas Philoctète dans l'Îsle d'Elbe de autoria anônima e data imprecisa (1814-1815) (Imagem 1), decodificando a imagem a partir da conjugação de dois pontos: Napoleão Bonaparte em Elba e sua ressignificação pelo mito grego de Filoctetes. Em um sentido amplo, tomamos o conceito de recepção do passado clássico como "as formas pelas quais material grego e romano foi transmitido, traduzido, citado, interpretado, reescrito, reimaginado $\mathrm{e}$ representado" "3. A noção de recepção em um primeiro momento aborda uma ideia, princípio

\footnotetext{
2 YOUNG, Norwood. Napoleon in Exile: Elba (1814-1815). Philadelphia: The John C. Winston Company, 1914, p. 09. Tradução nossa. No original: "The Elban episode in Napoleon's career has not received the attention it deserves. It reveals to us the man unencumbered by the weight of the Empire, and not yet given up to the pose for posterity".

${ }^{3}$ HARDWICK, Lorna; STRAY, Christopher. A Companion to Classical Receptions. S/l: Blackwell Publishing, 2008, p. 01. Tradução nossa. No original: "the ways in which Greek and Roman material has been transmitted, translated, excerpted, interpreted, rewritten, re-imaged and represented".
} 
ou conceito do passado recebido no presente, ou seja, recriado e reavaliado dentro de determinado aspecto ideológico.

O objetivo é apresentar uma forma incomum de uso da antiguidade, na qual Napoleão encarna o arqueiro grego pela sua deplorável condição. O texto divide-se em dois momentos: 1. O contorno do desenho, em que defino a problemática proposta e o conceito de caricatura utilizado para análise, além de realizar um levantamento bibliográfico da imagem; 2. A roupa de Napoleão em Filoctetes, em que é desenvolvida uma análise da caricatura.

\section{Imagem 1 - Philoctète dans l'Îsle d'Elbe (n'a jamais passé la Manche) (1814-15)}

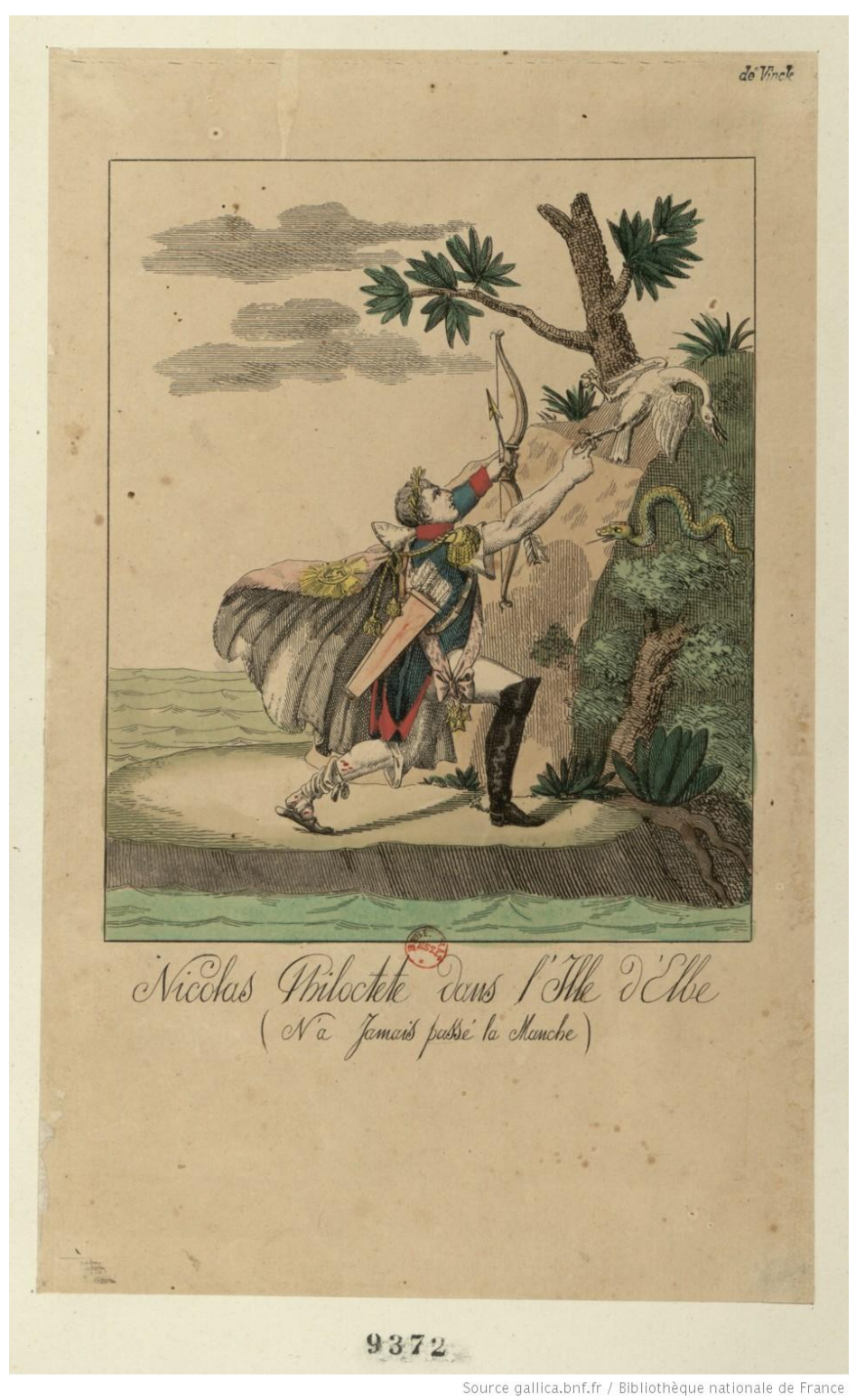

Bibliothèque Nationale de France. Disponível em: gallica.bnf.fr. 


\section{O contorno do desenho}

A caricatura é o testemunho de um discurso político. Moralizada ou destoante, ela pode ser usada para "auxiliar a reconstruir mentalidades ou atitudes políticas que desapareceram" napoleônico (1799-1815) poderia ser chamado de Golden Age, não apenas pela abundância de material produzido em muitos países, mas também pelo espectro de reações que o período proporcionou, entre defensores e detratores do Corso. A caricatura serviu como uma arma para dessacralizar a propaganda napoleônica, construindo um discurso que pela imagem risível também poderia acessar todas as camadas sociais, o que pela escrita nem sempre era possível.

Para pensar a caricatura em suas formas, é imprescindível recorrer a Ernest Gombricht e Ernst Kriss no clássico artigo The Principles of Caricature: "Como palavras de uma piada, as imagens das caricaturas estão sujeitas a esse reajuste (readjustment). O que impressiona é que o defeito dos sonhos em comparação com o pensamento consciente aqui se torna uma conquista em si. É claro, o processo primário precisa de um instrumento. Não é possível produzir uma piada que não esteja oculta na linguagem"5.

Sem adentrar nas dimensões da psicanálise, na relação entre caricatura e o chiste e no nascimento da caricatura propostos pelo artigo, o que nos interessa neste espaço é a noção de reajuste, ou como a caricatura opera a partir de reordenações de equivalências ou "semelhanças no dessemelhante"6. Os autores exemplificam o jogo de reajuste com o caso Poire (1827).

O editor Charles Philipon publicou no jornal Le Cherivari uma caricatura que comparava a cabeça do rei Louis-Philippe com uma pera (poire). O risível da semelhança não estava apenas no formato, mas também no fato de que poire era uma gíria para pessoas imbecis. A jocosidade de Philipon acabou sendo levada aos tribunais. O jornal habilmente conseguiu a inocência publicando uma espécie de rascunho, que mostrava os passos da feição da ilustração. $\mathrm{O}$ fato de poire ser uma palavra que remetia a outra interpretação era apenas

\footnotetext{
${ }^{4}$ BURKE, Peter. Testemunha Ocular: História e imagens. Bauru: Educs, 2004, p. 98.

${ }^{5}$ GOMBRICH, E. H.; KRIS, Ernst. The Principles of Caricature. British Journal of Medical Psychology, Vol. 17, 1938, p. 327. Tradução nossa. No original: "Like words in a joke, the pictures in caricatures are subjected to such readjustment. What impresses one is that the defect in dreams as compared with conscious thought here becomes an achievement in itself. Of course, the primary process must have an instrument to play on. It cannot produce a joke which is not hidden in the language".

${ }^{6}$ GOMBRICH, E. H. Arte e Ilusão: Um estudo da psicologia da representação pictórica. São Paulo: Martins Fontes, 1995, p. 365.
} 
uma coincidência, alegava o jornal. A figura da poire entrou no repertório político do momento e mostra como a caricatura opera entre trocadilho, semelhança e dessemelhança.

Para estratégias políticas, a caricatura ultrapassa o potencial humorístico. Ela é o que Annie Duprat qualifica como "une arme de combat"7 e desempenha o papel de termômetro da liberdade de expressão: "Ela é empregada facilmente em uma sociedade em que reina a liberdade de expressão e aparece como uma das condições necessárias para a existência da democracia". 8

Como "arma de combate", ela exerce abertamente uma operação anacrônica com seus atores. Duprat destaca que ela "comporta igualmente o sentido de exagero, de amplificação e as cenas burlescas das séries do "mundo ao contrário" cuja onda atravessa os séculos e em que os países, da Roma do século XVI à Rússia do século XVIII, podem ser integrados"9. É no rastro dessa temporalmente anacrônica, que opera por meio do "monde à l'envers" no âmbito do discurso político, que podemos identificar Napoleão no mito de Filoctetes.

A caricatura analisada é datada de forma imprecisa entre 1814 e 1815 , época de inconstância das forças políticas, na qual assumiu o poder na França o rei Louis XVIII e depois Napoleão retoma a coroa, que logo é devolvida a Louis XVIII. Duprat descreve o que chama de uma guerra das imagens entre Louis XVIII e Napoleão. Os partidários de Napoleão retratavam o rei como um glutão, que dilapidava e comia os tesouros do Estado, na figura de um porco ou de um elefante. Duprat destaca que "o registro da caricatura contra o imperador é muito mais unívoco e violento que aquela empregada contra o rei; ele denuncia um criminoso, um tirano responsável por muitas mortes nos campos de batalha da Europa inteira"10. A imagem satírica que coloca a roupa de Napoleão em Filoctetes pertence provavelmente a esses dois anos de violenta dessacralização da figura do imperador.

\footnotetext{
${ }^{7}$ DUPRAT, Annie. Histoire et images/histoire du visuel. In: DELACROIX, Christian; DOSSE, François; GARCIA, Patrick; OFFENSTADT, Nicolas (org.). Historiographies: Concepts et débats. Paris: Gallimard, 2010, p. 313.

${ }^{8}$ DUPRAT, Annie. Histoire et images/histoire du visuel. In: DELACROIX, Christian; DOSSE, François; GARCIA, Patrick; OFFENSTADT, Nicolas (org.). Historiographies: Concepts et débats. Paris: Gallimard, 2010, p. 313. Tradução nossa. No original: "elle se deploie aisément dans une société où regnet la liberte d'expression et apparaît comme l'une des conditions nécessaires à existence de la democratie".

${ }^{9}$ DUPRAT, Annie. Histoire et images/histoire du visuel. In: DELACROIX, Christian; DOSSE, François; GARCIA, Patrick; OFFENSTADT, Nicolas (org.). Historiographies: Concepts et débats. Paris: Gallimard, 2010, p. 314. Tradução nossa. No original: "comporte également le sens d'outrance, d'amplification et les scenes burlesques des séries du "monde à l'envers" dont la vogue traverse les siècles et les pays, de la Rome du XVI siècle à la Russie du XVIII' siécle, peuvent y être intégrées".

${ }^{10}$ DUPRAT, Annie. Une guerre des images: Louis XVIII, Napoléon et la France en 1815. Revue d'histoire moderne et contemporaine, tome 47, n. 3, juillet-septembre 2000, p. 499. Tradução nossa. No original: "Le registre de la caricature contre l'empereur est beaucoup plus univoque et violent que celui employé contre le roi; il dénonce un criminel, tyran responsable de tant de morts sur les champs de bataille de l'Europe entière".
} 
A primeira citação sobre Nicolas Philoctète dans l'Îsle d'Elbe aparece no monumental Napoleon in Caricature, 1795-1821, escrito por Alexander Meyrick Broadley em 1910, uma compilação que pretendia contar a história da caricatura napoleônica de um ponto de vista internacional, sem se fixar em um único país. A referência de apenas uma linha menciona a caricatura Nicolas Philoctète como marco do fracasso da invasão da Inglaterra: "O desaparecimento de Napoleão da arena da política prática não fez diminuir a veemência dos partidários dos Bourbons. O fracasso de sua invasão da Inglaterra foi motivo de escárnio no "Nicholas Philoctetes"11.

Durante o século XX, outros estudos também mencionaram o paralelo singular traçado pela caricatura entre Napoleão e Filoctetes. Cabe destacar entre menções breves o livro $L a$ Caricature contre Napoléon de Catherine Clerc $^{12}$ que, apesar de discutir brevemente a relação, expõe com destaque a associação. Nos estudos de recepção da tragédia grega, Seth Schein no prefácio ao Filoctetes destaca a imagem em relação ao quadro de Guillaume Guillon Lethière, Philoctète dans l'île déserte de Lemnos (1798) (Imagem 2):

\footnotetext{
Embora a maioria das recepções de Filoctetes no século XVIII se concentrem em sua agonia física e no sofrimento emocional de ter sido traído por seus companheiros e exilado de sua comunidade, algumas representações, após a Revolução Francesa, têm uma ênfase política. Por exemplo, Nicolas Philoctète dans l'îsle d'Elbe (1814-1815), uma imagem colorida de artista desconhecido, é uma caricatura antinapoleônica da conhecida pintura de Guillaume Guillon-Lethiere, Philoctète dans l'île déserte de Lemnos $(1798)^{13}$.
}

\footnotetext{
${ }^{11}$ BROADLEY, Alexander Meyrick. Napoleon in Caricature, 1795-1821. London: John Lane Co., 1911, 2 vv, pp. 59-60, v. 2. Tradução nossa. No original: "The temporary disappearance of Napoleon from the arena of practical politics brought about no diminution of the vehemence of the partisans of the Bourbons. His failure to invade England was gibed at in "Nicholas Philoctetes".

${ }^{12}$ CLERC, Catherine. La Caricature contre Napoléon. Paris: Promodis, 1985, p. 198.

${ }^{13}$ SCHEIN, Seth L. Introduction. In: SOPHOCLES. Philoctetes. Edited by Seth L. Schein. Cambridge: CUP, 2013, p. 52. Tradução nossa. No original: "While most eighteenth-century receptions of Philoktetes focus on his physical agony and emotional distress at having been betrayed by his comrades and exiled from his community, some representations, after the French revolution, have a political emphasis. For example, Nicolas Philoctete dans l'île d'Elbe (1814-15), a colour print by an unknown artist, is an anti-Napoleonic caricature of Guillaume Guillon-Lethiere's well-known painting, Philoktetes on the Desert island of Lemnos, Scaling the Rocks to Reach a Bird he has Killed (1798)."
} 


\section{Imagem 2 - Philoctète dans l'île déserte de Lemnos (1798), de Guillaume Guillon}

\section{Lethière.}

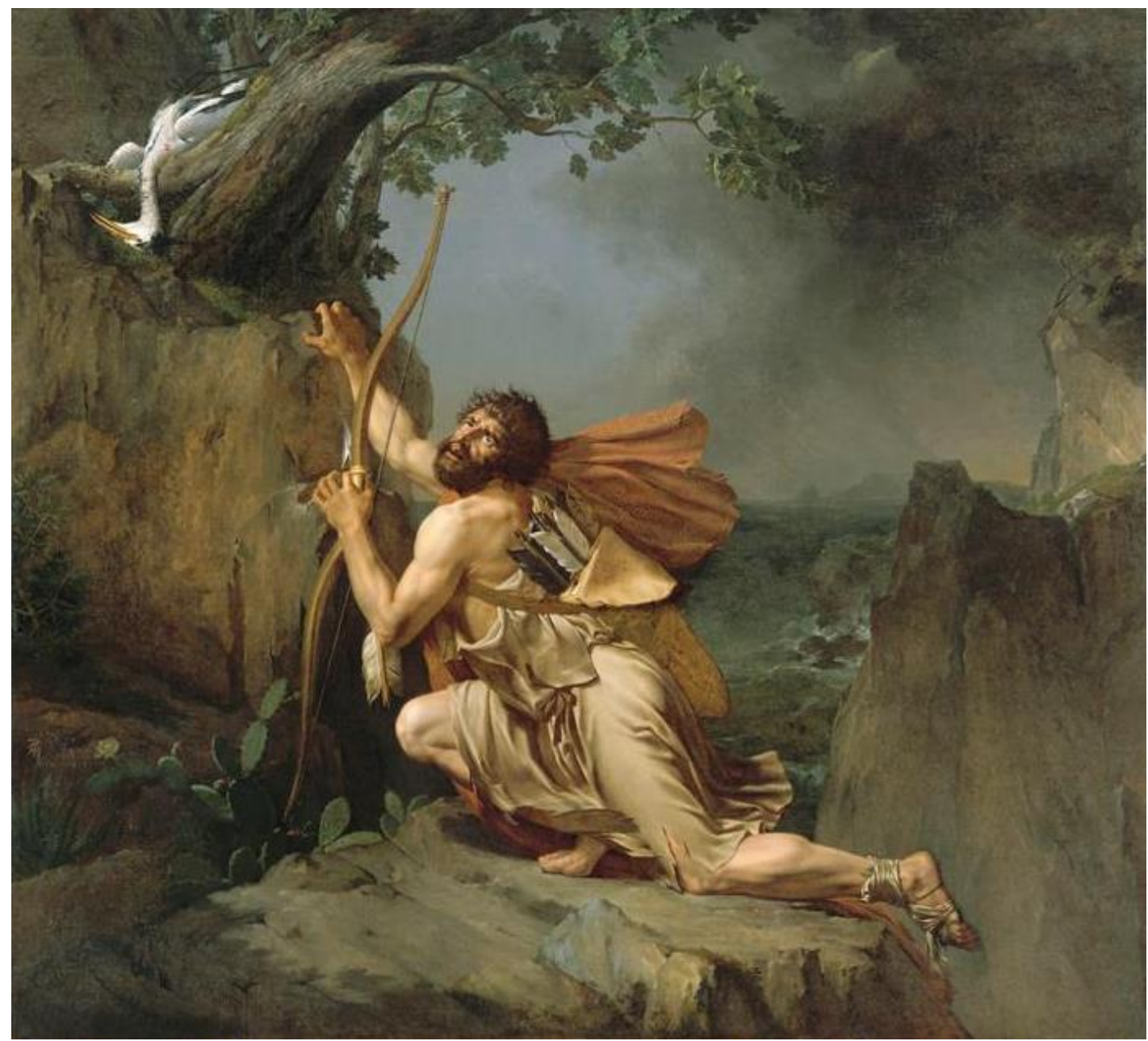

Wikipédia. Disponível em: https://commons.wikimedia.org/wiki/File:Guillaume_GuillonLethiere,_Philoctetes_on_the_Island_of_Lemnos.jpg.

A filóloga polonesa Agnieszka Fulińska, em seu artigo sobre a antiguidade na caricatura antinapoleônica, Ancient Topics in Anti-Napoleonic Caricature (1796-1821), dedica um brevíssimo espaço à análise da caricatura proposta: "O exílio em Elba produziu outra imagem, Nicolas Philoctète dans l'Îsle d'Elbe (N'a jamais passé La Manche), que alude ao destino miserável do herói homérico, mas aparentemente no esquema iconográfico geral em vez de com algum significado mais profundo"14.

\footnotetext{
${ }^{14}$ FULIŃSKA, Agnieszka. Ancient Topics in Anti-Napoleonic Caricature (1796-1821). In: DOMINAS, Konrad; WESOŁOWSKA, Elżbieta; TROCHA, Bogdan (ed.). Antiquity in Popular Literature and Culture. Newcastle: Cambridge Scholars Publishing, 2016, p. 139. Tradução nossa. No original: "The exile to Elba produced yet another image: "Nicolas Philoctète dans l'Ile d'Elbe (N'a jamais passé La Manche)", which alludes to the miserable fate of the Homeric hero, but apparently in the general iconographic scheme rather than with any deeper meaning".
} 
O texto que mais interessa para a proposta é de Philip Shaw, Napoleon as Philoctetes: Military Masculinity, Sacrifice and the Image of the Wound (2018). Shaw é o único dos autores que desenvolveu uma análise mais minuciosa e problematizadora da caricatura. Por meio de um itinerário interpretativo, o autor procura mapear relações entre corpo, sacrifício e masculinidade na esfera militar napoleônica, dedicando-se à análise de duas imagens, o quadro de Pierre Gautherot, Napoléon blessé au pied devant Ratisbonne (1810), e a caricatura Nicolas Philoctète (1814-1815).

Qualquer breve ou extensa biografia de Napoleão aponta a influência que poetas antigos como Homero e os imperadores romanos tiveram na formação do Imperador. Pascale Fautrier afirma que "Napoleão queria alçar-se à dimensão de heróis como Homero e Plutarco" "15. Essa ambição por pertencimento a linhagens clássicas do passado não é gratuita. Napoleão é herdeiro dos padrões da Arte Neoclássica e seu apelo a figuras da mitologia, que ajudaram a vincular as imagens dos reis a modelos antigos, bem como os estados absolutistas à grandeza imaginada de Grécia e Roma. A Revolução Francesa também usou modelos clássicos para destacar a grandeza de sua ambição.

Não podemos deixar de mencionar a importante obra de Peter Burke A Fabricação do Rei: A Construção da Imagem Pública de Luís XIV, que demonstra como o rei absolutista operacionalizou um grande repertório de imagens clássicas na construção de sua figura pública. Assim consciente do poder das imagens e dos usos do imaginário clássico, Napoleão e sua entourage desenvolvem uma estética de usos do passado clássico. A historiadora Susan Jaques destaca como a antiguidade, principalmente a romana, foi a inspiração estética do Império Napoleônico: “A antiguidade inspirou todos os aspectos do império de Napoleão, de seu corte de cabelo curto semelhante ao de Augusto à sua escolha do símbolo do Império, a águia de Júpiter. Da Roma Antiga, ele tomou emprestado imagens e símbolos de poder e autoridade, juntamente com seus poderosos rituais" ${ }^{\text {16. }}$.

Jaques demonstra como a construção de uma noção de antiguidade serviu de veículo para as ideias de grandeza do império napoleônico, que possuía uma iconografia oficial que sacralizava Napoleão e abusava da simbologia clássica. A ideia de passado era

\footnotetext{
${ }^{15}$ FAUTRIER, Pascale. Napoleão Bonaparte. Porto Alegre, RS: L\&PM, 2016, p. 25.

${ }^{16}$ JAQUES, Susan. The Caesar of Paris: Napoleon Bonaparte, Rome, and the Artistic Obsession that Shaped an Empire. New York: Pegasus Books, 2018, p. 07. Tradução nossa. No original: “Antiquity inspired all aspects of Napoleon's imperium-from his short Augustus-like haircut to his choice for the symbol of his Empire, the eagle of Jupiter. From ancient Rome, he borrowed images and symbols of power and authority, along with its powerful rituals".
} 
constantemente manipulada para que nele se moldasse qualquer aspecto que reforçasse as ideias de poder e ambição propostas por Napoleão e seus generais ${ }^{17}$.

Para Fulińska, é a saturação desse imaginário clássico que propiciará a produção de caricaturas com motivos da antiguidade relacionadas a Napoleão. Basta observar dois exemplos além do proposto para este texto: T. donnant une leçon de Grace et de Dignité Impériale (1813) de Elie (Imagem 3) e Le Tyran Démasqué (1815) de Jean-Baptiste l'Aîné Gautier (Imagem 4), para perceber que os usos do passado também eram feitos pelos críticos do Imperador: "Seria de se esperar, portanto, que essa onipresença de motivos antigos produzisse um efeito contrário, e que a propaganda antinapoleônica, que inundava a Europa desde o princípio da carreira de Bonaparte, explorasse os mesmos tópicos, transformando-os em imagens grotescas e caricaturas" ${ }^{\prime 18}$.

\footnotetext{
${ }^{17}$ JAQUES, Susan. The Caesar of Paris: Napoleon Bonaparte, Rome, and the Artistic Obsession that Shaped an Empire. New York: Pegasus Books, 2018, p. 07.

18 FULIŃSKA, Agnieszka. Ancient Topics in Anti-Napoleonic Caricature (1796-1821). In: DOMINAS, Konrad; WESOŁOWSKA, Elżbieta; TROCHA, Bogdan (ed.). Antiquity in Popular Literature and Culture. Newcastle: Cambridge Scholars Publishing, 2016, p. 130. Tradução nossa. No original: "One might, therefore, expect that this omnipresence of ancient motifs should produce a counter effect, and the anti-Napoleonic propaganda, which was flooding Europe from the very beginning of Bonaparte's career, should exploit the same topics, turning them into grotesques and caricatures".
} 
Imagem 3 - T. donnant une leçon de Grace et de Dignité Impériale” (1813), de Elie.

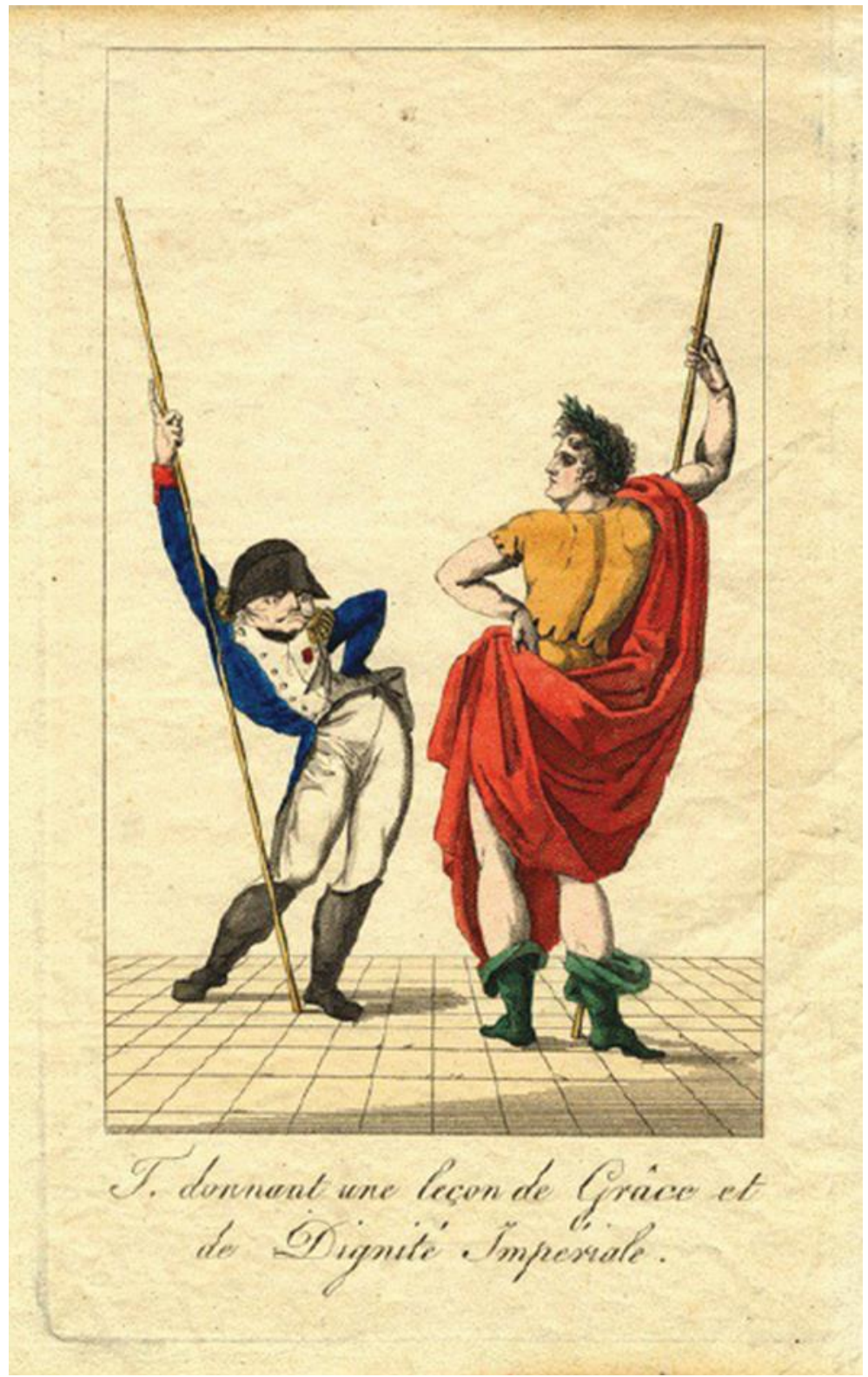

Fondation Napoléon. 


\section{Imagem 4 - Le Tyran Démasqué (1815), de Jean-Baptiste l'Aîné Gautier.}

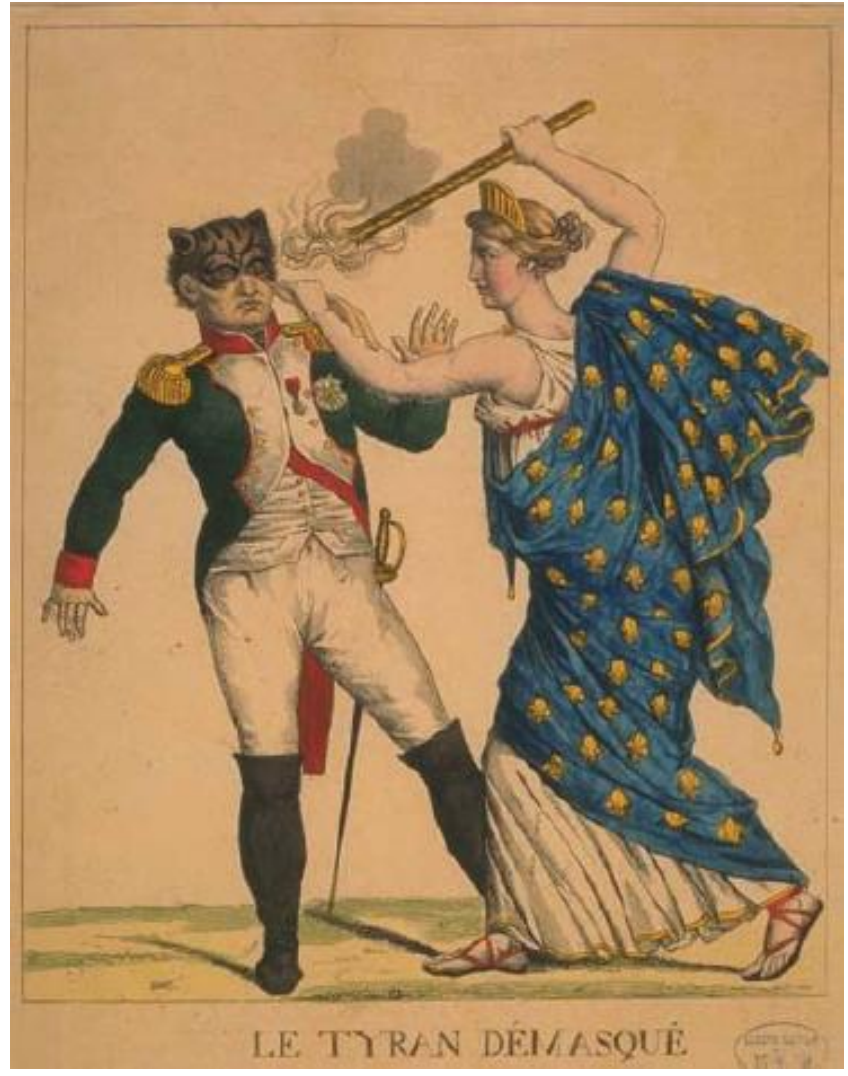

Arenenberg, Napoleonmuseum. Fondation Napoléon.

Tentaremos demostrar na segunda parte como a caricatura Nicolas Philoctète dans l'Îsle d'Elbe segue o padrão de caricatura como arma de combate, subvertendo a lógica elogiosa dos usos do passado para a busca de efeito do ridículo, operando de acordo com a lógica do reajuste (readjustment) de Gombricht e Kriss na caricatura, que opera a partir de reordenações de equivalências.

\section{A roupa de Napoleão em Filoctetes}

Em seu pequeno livro sobre Napoleão em Elba, Norman Mackenzie descreve o seguinte retrato de Napoleão na ilha:

Napoleão em Elba foi na verdade a perfeita miniatura do Homem do Destino, com suas virtudes e defeitos reduzidos à dimensão humana, sem campo de ação para sua abundante energia exceto o do minúsculo reino em que seus inimigos, com escárnio, o tinham instalado; e o contraste entre as glórias passadas e a adversidade do momento era especialmente humilhante ${ }^{19}$.

\footnotetext{
${ }^{19}$ MACKENZIE, Norman. Napoleão: A Fuga de Elba. Rio de Janeiro: Globo Livros, 2018, pp. 01-02.
} 
Mackenzie evoca na figura de Napoleão um contorno trágico, como se Elba fosse um refúgio de um homem além do tempo, como se erros e acertos do Imperador não pertencessem à esfera humana. Não deixa de ser incrível que Mackenzie não resgate durante seu livro alguma comparação entre o Corso humilhado e o arqueiro Filoctetes, pois a descrição remete a um homem desertado como o guerreiro homérico.

$\mathrm{Na}$ esteira da tragicidade solitária evocada por Mackenzie que pode remeter a contornos míticos, é preciso então explicar algumas considerações sobre o mito de Filoctetes para poder identificar os elementos de reconhecimento na caricatura.

A fonte mais conhecida sobre Filoctetes é a tragédia homônima de Sófocles, encenada em 409 a.C. Em linhas gerais ${ }^{20}$, Filoctetes, filho do argonauta Peante, era um guerreiro hábil no manuseio do arco. Não bastasse sua excelente habilidade, ele tinha recebido do próprio Héracles, por acender sua pira funerária, o arco e as flechas de Apolo, que nunca erravam o alvo. $\mathrm{O}$ arqueiro embarcou a caminho de Troia com os helenos, mas teria sido picado por uma serpente em uma parada na pequena ilha de Crise. Algumas versões apontam que ele profanou um templo sagrado na ilha, e a picada era consequência desse ato. A ferida de Filoctetes foi no pé, causando dores inumanas que o reduziam a uma condição animal. Os generais gregos acabaram deixando o guerreiro na ilha deserta de Lemnos. Posteriormente, decorridos então nove anos de combate na planície de Troia, um adivinho vaticinou que a guerra só seria vencida com Filoctetes, se ele fosse reintegrado aos campos de batalha. Os três trágicos, Ésquilo, Sófocles e Eurípides, escreveram tragédias sobre o episódio da persuasão para o retorno de Filoctetes aos campos de batalha. Infelizmente, apenas a tragédia de Sófocles chegou até nós inteira.

A caricatura é explícita ao indicar que Napoleão deve ser visto como Filoctetes: a legenda satírica o chama de "Nicolas Philoctète". A caricatura antinapoleônica produzida na França utilizava o termo "Nicolas", apelido de Napoleão na época de estudante, que também fazia coro a canções que o identificavam como tirano: "A bas Nicolas! A bas le tyran"21.

No corpo estilizado em posição suplicante, encontramos o Imperador em seu antigo traje, agora em situação de trapos. Em sua perna, localizamos um curativo que indica a ferida causada pela cobra, que também é colocada na caricatura. Em sua mão, o arco, e em suas

\footnotetext{
${ }^{20}$ Para compreender as variantes do mito, ver The Greek Myths, de Robert Graves (1960).

${ }^{21}$ SHAW, Philip. Napoleon as Philoctetes: Military Masculinity, Sacrifice and the Image of the Wound. Journal for Eighteenth-Century Studies, vol. 41, n. 4, 2018, p. 569.
} 
costas, o estojo das flechas sagradas de Héracles. Em sua cabeça, temos a coroa de louros, símbolo dos generais romanos, que era marca constante na representação do Imperador.

No espectro de imagens de desolação e fracasso imputadas por seus adversários e recebidas na caricatura, Napoleão passou a receber cada vez mais um tipo específico de representação na caricatura, que remetia à morbidez de quem desejava uma morte próxima para o Imperador e também à conclusão de que a diabólica figura, responsável direta ou indiretamente pelas mortes no campo de batalha, foi despejada onde lhe cabia, no inferno, como defende Ian Haywood no livro Romanticism and Caricature:

A transformação caricatural de Napoleão em uma figura fantástica simultaneamente real, excepcional e demonicamente sobrenatural - reforçou a autoridade cultural da sátira visual e abriu caminho para a retomada das guerras de propaganda domésticas no período do pós-guerra. As reviravoltas dos últimos estágios da carreira de Napoleão aumentaram a força espectropolítica da imaginação "esqueletizada". Ninguém poderia ter previsto a forma notável com que a arte imitaria a vida: como se estivesse seguindo o roteiro de Milton e exaltando sua reputação satânica, Napoleão foi banido para o Inferno (Elba ou Hell-Bay, Baía do Inferno, nos cartuns), escapando para causar ainda mais destruição em uma Europa "consternada" 22 .

Como nos mostra a caricatura Sujet allégorique (Imagem 5) feita em setembro de 1815 por Lacroix, Napoleão é guiado por um esqueleto que representa a morte seguido como mostra a legenda pela ambição, pela miséria e pela guerra, todas caracterizadas com indumentárias antigas.

\footnotetext{
${ }^{22}$ HAYWOOD, Ian. Romanticism and Caricature. New York: CUP, 2013, p. 86. Tradução nossa. No original: "The caricature transformation of Napoleon into an uncanny figure - simultaneously real, larger than life and demonically other-worldly - boosted visual satire's cultural authority and paved the way for the resumption of domestic propaganda wars in the post-war period. The twists and turns of the last stages of Napoleon's career augmented the spectropolitical force of the 'skeletonised' imagination. No one could have foreseen the remarkable way in which life imitated art: as if he were following the Miltonic script and glorying in his Satanic reputation, Napoleon was banished to Hell (Elba or 'Hell-Bay' in the cartoons) only to escape and wreak further havoc on 'confounded' Europe".
} 


\section{Imagem 5 - Sujet allégorique (1815), de Lacroix.}

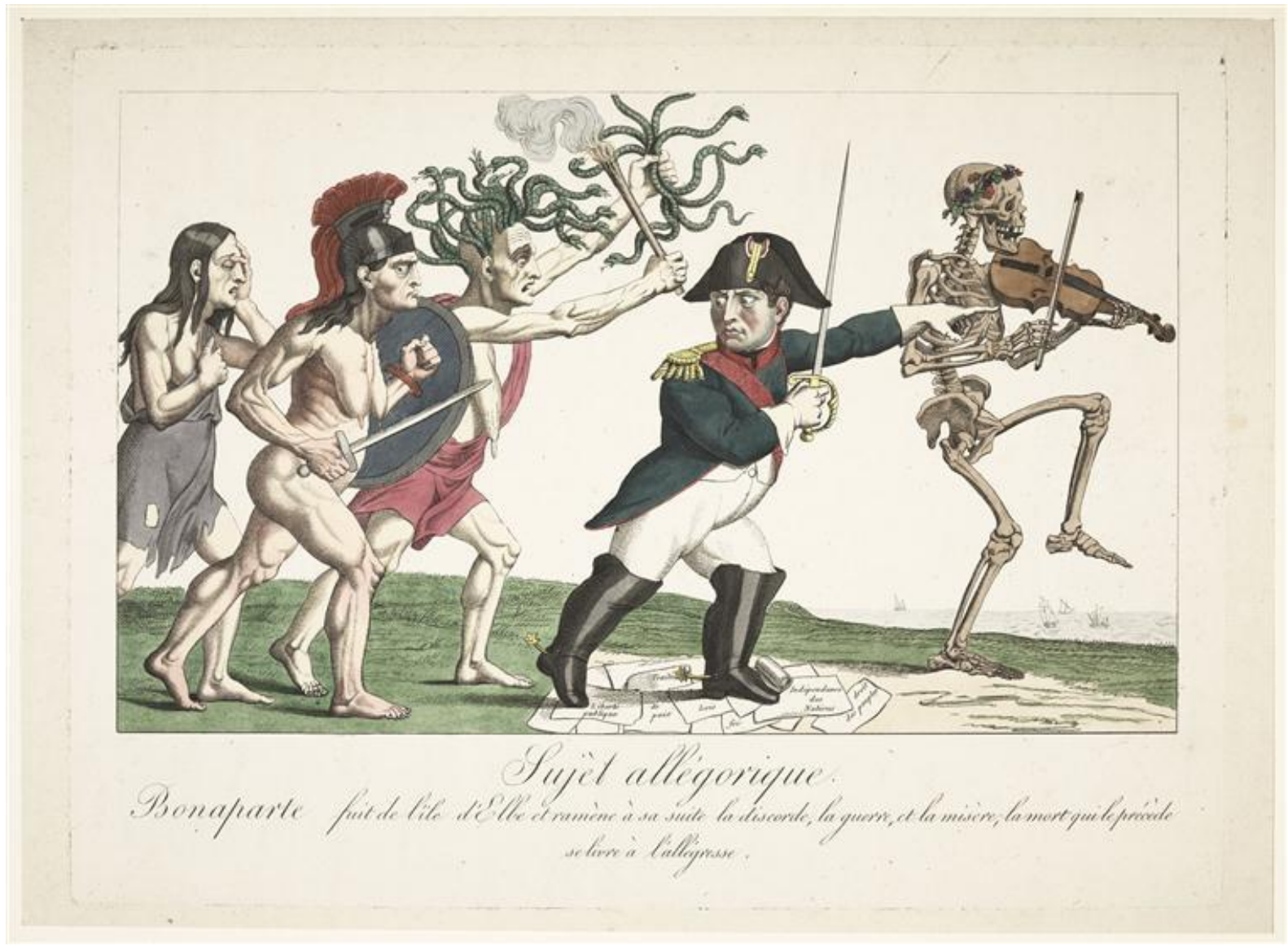

Arenenberg, Napoleonmuseum. Fondation Napoléon.

A associação entre Napoleão e Filoctetes é estabelecida a partir desse parâmetro de isolamento. A figura destaca a condição de fracasso do Imperador, retratado como um Filoctetes abandonado aos gritos por seu ferimento em uma pequena ilha, que ali deve permanecer para que o mundo restabeleça sua ordem. Não passou despercebido para aqueles que analisaram a caricatura que ela é uma releitura satírica do quadro do pintor neoclássico Guillon Lethière (1760-1832), Philoctète dans l'île déserte de Lemnos (1798). Philip Shaw destaca o seguinte paralelo entre a pintura e a caricatura:

Como o herói na representação de Lethière, Napoleão, com um curativo na perna ferida, é retratado tentando alcançar um pássaro (possivelmente uma cegonha branca, símbolo da paz mas também, para os antigos gregos, um animal protegido, cujo abate era punível com a morte), um detalhe que assume significado especial à luz dos apelos para que o usurpador tivesse a morte que merecia ${ }^{23}$.

\footnotetext{
${ }^{23}$ SHAW, Philip. Napoleon as Philoctetes: Military Masculinity, Sacrifice and the Image of the Wound. Journal for Eighteenth-Century Studies, vol. 41, n. 4, 2018, p. 569. Tradução nossa. No original: "Like the hero in Lethière's depiction, Napoleon, with a bandage on his injured leg, is shown reaching for a bird - possibly a white stork, symbolic of peace but also, for the ancient Greeks, a protected animal, the killing of which is
} 
A caricaturização da impressionante e emotiva pintura de Lethière, com todos os elementos de reconhecimento do mito - o pé ferido, as flechas, o arco e a solidão da ilha demostram a ideia de "reajuste" apresentada por Gombrich e Kris. Não é utilizada no Nicolas Philoctète a clássica formulação de ressaltar a barriga ou a altura de Napoleão, tão comum nas outras peças satíricas. Tampouco ele é animalizado, ou revestido de morbidez. A ironia reside em emular um corpo clássico e assumir romanticamente o corpo de um herói grego, vestido com trajes do Imperador. O Napoleão admirador dos césares e cultuador de uma memória elogiosa da antiguidade é comparado a um guerreiro grego esquecido, abandonado e ferido.

A contradição da caricatura, do que consideramos um "curioso caso", é que não podemos saber o quanto o artista responsável pelo deboche satírico conhecia o mito de Filoctetes, pois nas versões míticas sabemos que o guerreiro retorna aos campos de batalha e ajuda a armada grega a vencer a guerra de Troia. Por que utilizar a figura de um herói que em sua solidão encontraria um caminho para o retorno e teria uma vitória? Napoleão não terá seu fim em Elba. A ilha será um capítulo, que antecede feitos considerados gloriosos na vida do Imperador. A explicação da contradição pode ser o desconhecimento do enredo mítico, ou simplesmente a utilização do quadro de Lethière para ressaltar o abandono do Corso com a imagem do arqueiro abandonado em andrajos.

Nos caminhos dos usos do passado, Filoctetes é um mito com usos variados. Na pintura, como mostra a tela de Guillon Lethière, é usado para descrever a fragilidade do homem frente à natureza. Na literatura, foi utilizado por exemplo por André Gide em seu Philoctéte (1898) para demostrar uma moralidade isolacionista. ${ }^{24}$ Assim, o herói grego é uma figura que pode até mesmo demonstrar para o público moderno uma noção de piedade e inconformismo. A caricatura utilizou Filoctetes para ressaltar o isolamento, mas contraditoriamente Filoctetes serviria também para evocar o retorno glorioso de Napoleão. A contradição da imagem só pode ser notada a posteriori, mas mesmo assim se configura um caso curioso de reviravolta de expectativa.

punishable by death - a detail that takes on special significance in light of the calls for the usurper to meet his just demise".

${ }^{24}$ Para mais informações, ver o artigo Filoctetes em Sófocles, André Gide e Heiner Müller de Fernando Brandão dos Santos (1993). 


\section{Conclusão}

Trazer o tema da caricatura napoleônica e sua relação com a antiguidade é um desafio de configurar uma análise em duas dimensões: a primeira é a conjugação dos motivos e do entorno político da caricatura em questão; o seguinte é uma ideia de antiguidade como propaganda e consequentemente antipropaganda que é realizada pelo desenho satírico. Tentamos demostrar que a caricatura Nicolas Philoctète dans l'Îsle d'Elbe pertence a um momento, entre 1814 e 1815 , em que havia uma guerra de imagens declarada entre apoiadores do rei Louis XVIII e partidários do Imperador Napoleão. A recriação de um Napoleão na figura de Filoctetes, ou "A roupa de Napoleão em Filoctetes", é um caso emblemático, pela contradição do arqueiro grego e pela utilização depreciativa do mito antigo.

Em um momento em que vivemos cada vez mais imersos em uma cultura da imagem, e no qual a propaganda política é feita cada vez mais de desinformação e da ridicularização do outro, em que a notícia é minada pela "noticia falsa", pelo falso reapropriado como verdadeiro, e em que o boato ganha do fato em relevância, rever esse caso específico da caricatura napoleônica nos ajuda a perceber como a sátira se constituiu em uma arma do jogo político. O jogo da caricatura pertence à política moderna, e um regime que censura a caricatura não pode se denominar democrático. Mas infelizmente, no nosso tempo, já elegemos as caricaturas, deixando pouco trabalho à pena dos caricaturistas.

\section{REFERÊNCIAS BILIOGRÁFICAS}

BROADLEY, Alexander Meyrick. Napoleon in Caricature, 1795-1821. London: John Lane Co., 1911, 2 vv.

BURKE, Peter. Testemunha Ocular: História e imagens. Bauru: Educs, 2004.

CLERC, Catherine. La Caricature contre Napoléon. Paris: Promodis, 1985.

DUPRAT, Annie. Une guerre des images: Louis XVIII, Napoléon et la France en 1815. Revue d'histoire moderne et contemporaine, tome 47, n. 3, juillet-septembre 2000, pp. 487-504.

DUPRAT, Annie. Histoire et images/histoire du visuel. In: DELACROIX, Christian; DOSSE, François; GARCIA, Patrick; OFFENSTADT, Nicolas (org.). Historiographies: Concepts et débats. Paris: Gallimard, 2010, pp. 307-317.

FAUTRIER, Pascale. Napoleão Bonaparte. Porto Alegre, RS: L\&PM, 2016. 
FULIŃSKA, Agnieszka. Ancient Topics in Anti-Napoleonic Caricature (1796-1821). In: DOMINAS, Konrad; WESOŁOWSKA, Elżbieta; TROCHA, Bogdan (ed.). Antiquity in Popular Literature and Culture. Newcastle: Cambridge Scholars Publishing, 2016, pp. 127156.

GOMBRICH, E. H.; KRIS, Ernst. The Principles of Caricature. British Journal of Medical Psychology, Vol. 17, 1938, pp. 319-42.

GOMBRICH, E. H. Arte e Ilusão: Um estudo da psicologia da representação pictórica. São Paulo: Martins Fontes, 1995.

GRAVES, Robert. The Greek Myths. Harmondsworth, England: Penguin Books, 1960.

HARDWICK, Lorna; STRAY, Christopher. A Companion to Classical Receptions. S/l: Blackwell Publishing, 2008.

HAYWOOD, Ian. Romanticism and Caricature. New York: CUP, 2013.

JAQUES, Susan. The Caesar of Paris: Napoleon Bonaparte, Rome, and the Artistic Obsession that Shaped an Empire. New York: Pegasus Books, 2018.

MACKENZIE, Norman. Napoleão: A Fuga de Elba. Rio de Janeiro: Globo Livros, 2018.

SANTOS, Fernando Brandão dos. Filoctetes em Sófocles, André Gide e Heiner Müller. Itinerários: Revista de Literatura, n. 6, 1993.

SCHEIN, Seth L. Introduction. In: SOPHOCLES. Philoctetes. Edited by Seth L. Schein. Cambridge: CUP, 2013, pp. 01-59.

SHAW, Philip. Napoleon as Philoctetes: Military Masculinity, Sacrifice and the Image of the Wound. Journal for Eighteenth-Century Studies, vol. 41, n. 4, 2018, pp. 559-577.

YOUNG, Norwood. Napoleon in Exile: Elba (1814-1815). Philadelphia: The John C. Winston Company, 1914. 